\title{
Associations of MTHFR C677T and MTRR A66G Gene Polymorphisms with Metabolic Syndrome: A Case-Control Study in Northern China
}

\section{Boyi Yang ${ }^{1}$, Shujun Fan ${ }^{1}$, Xueyuan Zhi ${ }^{1}$, Da Wang ${ }^{1}$, Yongfang Li ${ }^{1}$, Yinuo Wang ${ }^{2}$, Yanxun Wang ${ }^{2}$, Jian Wei ${ }^{3}$, Quanmei Zheng ${ }^{1}$ and Guifan Sun ${ }^{1, *}$}

1 Environment and Non-Communicable Disease Research Center, School of Public Health, China Medical University, Shenyang 110013, China; E-Mails: boyiyangcmu@163.com (B.Y.); fanfan0721yk1@163.com (S.F.); zhixy90smile@126.com (X.Z.); 472594283@163.com (D.W.); liyongfang17@163.com (Y.L.); qmzheng@mail.cmu.edu.cn (Q.Z.)

2 Division of Molecular Preventive Medicine, Shanghai Institute of Targeted Therapy and Molecular Medicine, Shanghai 200433, China; E-Mails: 13817895706@163.com (Y.W.); wangyanxun@genechina.com (Y.W.)

3 Brain Disease Center, Tianjin Dagang Oil Field General Hospital, Tianjin 300280, China; E-Mail: weijiantianjin@163.com

* Author to whom correspondence should be addressed; E-Mail: sungf@mail.cmu.edu.cn; Tel./Fax: +86-24-2326-1744.

External Editor: Emil Alexov

Received: 21 September 2014; in revised form: 3 November 2014 / Accepted: 12 November 2014 / Published: 25 November 2014

\begin{abstract}
Prior evidence indicates that homocysteine plays a role in the development of metabolic syndrome (MetS). Methylenetetrahydrofolate reductase (MTHFR) C677T and methionine synthase reductase (MTRR) A66G polymorphisms are common genetic determinants of homocysteine levels. To investigate the associations of the MTHFR C677T and MTRR A66G polymorphisms with MetS, 692 Chinese Han subjects with MetS and 878 controls were recruited. The component traits of MetS and the MTHFR C677T and MTRR A66G genotypes were determined. A significant association was observed between the MTHFR $677 \mathrm{~T}$ allele and increased risk of MetS, high fasting blood glucose, high waist circumference, and increasing number of MetS components. The MTRR A66G polymorphism was associated with an increased risk of MetS when combined with the MTHFR 677TT genotype, although there was no association found between MetS
\end{abstract}


and MTRR A66G alone. Furthermore, the MTRR 66GG genotype was associated with high fasting blood glucose and triglycerides. Our data suggest that the MTHFR 677T allele may contribute to an increased risk of MetS in the northern Chinese Han population. The MTRR A66G polymorphism is not associated with MetS. However, it may exacerbate the effect of the MTHFR C677T variant alone. Further large prospective population-based studies are required to confirm our findings.

Keywords: MTHFR; MTRR; polymorphism; metabolic syndrome; China

\section{Introduction}

Metabolic syndrome (MetS) is characterized through a cluster of various metabolic abnormalities, including central obesity, dyslipidemia, elevated blood pressure (BP) and high glucose concentrations. Available evidence shows that the prevalence of MetS is rapidly increasing worldwide [1,2]. In China, the prevalence has been estimated as $13.7 \%$ in men and $17.8 \%$ in women, and shows geographical and age variations [3]. MetS and its individual components have been reported to be associated with increased risk of diabetes and cardiovascular diseases, as well as with high all-cause mortality [4-6]. The etiology of MetS is complicated because many genetic and environmental factors may be involved [6]. Homocysteine (Hcy) is a sulfur-containing amino acid derived from methionine metabolism. Several studies have linked hyperhomocysteinemia (HHcy) to MetS and its individual components [7-12], and it has even been described as an integral component of MetS in rats [13]. Potential mechanisms linking HHcy with MetS and its components include promoting endothelial dysfunction, inducing insulin resistance, and influencing DNA methylation status [10,14-17]. Because of the relationship between Hcy and MetS, factors influencing the plasma Hcy levels may potentially relate to MetS.

Plasma Hcy levels are controlled and modulated by multiple genetic and environmental factors and their interactions. Among these factors, methylenetetrahydrofolate reductase (MTHFR) C677T and methionine synthase reductase $(M T R R)$ A66G polymorphisms are the major genetic causes. MTHFR, which catalyzes the conversion of 5,10-methylenetetrahydrofolate to 5-methyltetrahydrofolate, is an enzyme necessary for the Hcy metabolic pathway and has been associated with methylation of genomic DNA. Polymorphism of the MTHFR gene at position 677 from $\mathrm{C}$ to $\mathrm{T}$ decreases its enzyme activity, leading to accumulation of Hcy especially under conditions of low dietary folate [18]. Previous studies also showed that the MTHFR 677T allele could cause DNA hypomethylation, which has been associated with MetS and its components [15,19]. MTRR is another important enzyme involved in Hcy metabolism, which is responsible for the remethylation of Hcy to methionine via a vitamin $\mathrm{B}_{12}$ dependent reaction [20]. The most common polymorphism in the MTRR gene is the substitution of A for $\mathrm{G}$ at position 66, which adversely influences the enzyme activity and thus is considered as a genetic risk factor for HHcy [20]. The MTRR A66G polymorphism may also induce DNA hypomethylation by regulation of Hcy levels [14]. Additionally, some studies suggested additive or synergistic effects of the MTHFR C677T and MTRR A66G polymorphisms on plasma Hcy levels [21].

Previous epidemiological studies have indicated that carriers of the MTHFR 677T allele or 677TT genotype were at significantly increased risk of developing hypertension [22], type 2 diabetes [23], 
dyslipidemia [24] and obesity [25], which are all important factors in the diagnosis of MetS. With respect to the MTRR A66G polymorphism, its effect on MetS is not as well studied as that of the MTHFR C677T polymorphism and, to date, no study has directly explored the relationship between the MTRR A66G polymorphism and MetS. Additionally, some studies have investigated the effect of the MTHFR C677T polymorphism on MetS in schizophrenia [26,27], type 2 diabetes [28], stroke [29] and colorectal cancer patients [30], however, few studies have examined the risk of MetS in the general population without severe disease. In China, due to the changing life styles and dietary habits, the rates of MetS and its related diseases such as stroke, coronary heart disease, hypertension and diabetes, are markedly increasing, especially in northern areas [31]. Previous studies reported that residents of northern China had higher plasma Hcy concentrations than those living in southern China [32]. Our group also has observed high frequencies of the MTHFR 677TT genotype and 677T allele among Chinese northerners [33]. Based on the above considerations, we hypothesized that the MTHFR C677T and MTRR A66G polymorphisms, either independently or in combination, might be associated with MetS in a northern Chinese Han population. We therefore conducted a case-control study to investigate the above hypothesis in a population living in Tianjin, which is a municipality located in northern China.

\section{Results}

\subsection{Demographic and Clinical Characteristics of Study Subjects}

Table 1 summarizes the demographic and clinical characteristics of the MetS patients and controls. The distribution of sex and age was similar between the two groups. However, significant differences existed between the two groups in body mass index (BMI), waist circumference (WC), systolic blood pressure (SBP), diastolic blood pressure (DBP), fasting blood glucose (FBG), triglyceride (TG), total cholesterol (TC), high density lipoprotein cholesterol (HDL-C) and low density lipoprotein cholesterol (LDL-C) levels.

Table 1. Demographic and clinical characteristics of study subjects.

\begin{tabular}{cccc}
\hline Variables & Patients & Controls & $\boldsymbol{p}$ Value \\
\hline Gender $(\mathrm{M} / \mathrm{F})$ & $541 / 151$ & $659 / 219$ & 0.1478 \\
Age $($ year $)$ & $48.82 \pm 10.10$ & $46.54 \pm 9.93$ & 0.0621 \\
BMI $\left(\mathrm{kg} / \mathrm{m}^{2}\right)$ & $27.37 \pm 3.55$ & $24.14 \pm 3.14$ & $<0.0001$ \\
WC $(\mathrm{cm})$ & $94.35 \pm 8.46$ & $84.52 \pm 9.08$ & $<0.0001$ \\
SBP $(\mathrm{mmHg})$ & $141.40 \pm 17.88$ & $125.30 \pm 17.11$ & $<0.0001$ \\
DBP $(\mathrm{mmHg})$ & $90.05 \pm 12.02$ & $79.74 \pm 11.81$ & $<0.0001$ \\
FBG $(\mathrm{mmol} / \mathrm{L})$ & $5.79 \pm 1.45$ & $5.02 \pm 0.72$ & $<0.0001$ \\
TG $(\mathrm{mmol} / \mathrm{L})$ & $2.12 \pm 1.79$ & $1.01 \pm 0.60$ & $<0.0001$ \\
TC $(\mathrm{mmol} / \mathrm{L})$ & $5.13 \pm 1.04$ & $4.91 \pm 0.91$ & $<0.0001$ \\
HDL-C $(\mathrm{mmol} / \mathrm{L})$ & $1.03 \pm 0.25$ & $1.26 \pm 0.32$ & $<0.0001$ \\
LDL-C $(\mathrm{mmol} / \mathrm{L})$ & $2.82 \pm 0.98$ & $2.69 \pm 0.88$ & 0.0081 \\
\hline
\end{tabular}

Abbreviations: M, male; F, female; BMI, body mass index; WC, waist circumference; SBP; systolic blood pressure; DBP, diastolic blood pressure; FBG, fasting blood glucose; TG, triglycerides; TC, total cholesterol; HDL-C, high density lipoprotein cholesterol; LDL-C, low density lipoprotein cholesterol. 


\subsection{Genotypic and Allelic Frequencies}

Genotypic and allelic frequencies for the MTHFR C677T and MTRR A66G polymorphisms are presented in Tables 2 and 3, respectively. Genotype distributions of the two polymorphisms were consistent with Hardy-Weinberg equilibrium in both patients $(p=0.7610)$ and controls $(p=0.6383)$. No significant differences in the prevalence of the MTHFR C677T and MTRR A66G polymorphisms were found between males and females ( $p=0.3603$ and 0.5202 , respectively).

For the MTHFR C677T polymorphism, significant differences were found in the genotypic $(p=0.0082)$ and allelic $(p=0.0091)$ frequencies between the patients and controls. For the MTRR A66G polymorphism, no statistically significant differences were detected between the two groups in either the genotypic frequencies ( $p=0.2704)$ or allelic frequencies $(p=0.4012)$.

Table 2. Association of methylenetetrahydrofolate reductase (MTHFR) C677T polymorphism with metabolic syndrome (MetS) risk.

\begin{tabular}{ccccccc}
\hline $\begin{array}{c}\text { Genetic } \\
\text { Model }\end{array}$ & $\begin{array}{c}\text { Patients } \\
(\boldsymbol{n}=\mathbf{6 9 2})\end{array}$ & $\begin{array}{c}\text { Controls } \\
(\boldsymbol{n}=\mathbf{8 7 8})\end{array}$ & $\begin{array}{c}\text { Crude OR } \\
(\mathbf{9 5 \%} \text { CI) }\end{array}$ & $\boldsymbol{p}$ Value & $\begin{array}{c}\text { Adjusted OR } \\
(\mathbf{9 5 \%} \text { CI) }\end{array}$ & $\boldsymbol{p}$ Value \\
\hline $\begin{array}{c}\text { Codominant } \\
\text { CC }\end{array}$ & $129(18.6)$ & $202(23.0)$ & 1.00 & & 1.00 & \\
CT & $335(48.4)$ & $431(49.1)$ & $1.22(0.94-1.58)$ & 0.1432 & $1.24(0.95-1.62)$ & 0.1129 \\
TT & $228(32.9)$ & $245(27.9)$ & $1.46(1.10-1.94)$ & 0.0097 & $1.48(1.11-1.98)$ & 0.0076 \\
\hline $\begin{array}{c}\text { Dominant } \\
\text { CC }\end{array}$ & $129(18.6)$ & $202(23.0)$ & 1.00 & & 1.00 & \\
CT+TT & $563(81.4)$ & $676(77.0)$ & $1.30(1.02-1.67)$ & 0.0355 & $1.33(1.03-1.71)$ & 0.0266 \\
\hline Recessive & & & & & \\
CC+CT & $464(67.1)$ & $633(72.1)$ & 1.00 & & 1.00 & \\
TT & $228(32.9)$ & $245(27.9)$ & $1.27(1.02-1.58)$ & 0.0306 & $1.27(1.02-1.59)$ & 0.0302 \\
\hline Allelic & & & & & \\
C & $593(42.8)$ & $835(47.6)$ & 1.00 & & 1.00 & \\
T & $791(57.2)$ & $921(52.4)$ & $1.21(1.05-1.39)$ & 0.0086 & $1.22(1.10-1.34)$ & 0.0002 \\
\hline
\end{tabular}

Abbreviations: MTHFR, methylenetetrahydrofolate reductase; OR, odds ratio; CI, confidence interval;

MetS, metabolic syndrome; ${ }^{a}$ Adjusted for age and sex.

Table 3. Association of methionine synthase reductase (MTRR) A66G polymorphism with MetS risk.

\begin{tabular}{ccccccc}
\hline $\begin{array}{c}\text { Genetic } \\
\text { Model }\end{array}$ & $\begin{array}{c}\text { Patients } \\
(\boldsymbol{n}=\mathbf{6 9 2})\end{array}$ & $\begin{array}{c}\text { Controls } \\
(\boldsymbol{n}=\mathbf{8 7 8})\end{array}$ & $\begin{array}{c}\text { Crude OR } \\
(\mathbf{9 5 \%} \text { CI) }\end{array}$ & $\boldsymbol{p}$ Value & $\begin{array}{c}\text { Adjusted OR } \\
(\mathbf{9 5 \%} \text { CI) }\end{array}$ & $\boldsymbol{p}$ Value \\
\hline Codominant & & & & & & \\
AA & $391(56.5)$ & $501(57.1)$ & 1.00 & & 1.00 & \\
AG & $245(35.4)$ & $324(36.9)$ & $0.97(0.78-1.20)$ & 0.7705 & $0.99(0.80-1.23)$ & 0.9444 \\
GG & $56(8.1)$ & $53(6.0)$ & $1.35(0.91-2.02)$ & 0.1359 & $1.37(0.92-2.05)$ & 0.1270 \\
\hline Dominant & & & & & & \\
AA & $391(56.5)$ & $501(57.1)$ & 1.00 & & 1.00 & \\
AG + GG & $301(43.5)$ & $377(42.9)$ & $1.02(0.84-1.25)$ & 0.8244 & $1.05(0.85-1.28)$ & 0.6683 \\
\hline
\end{tabular}


Table 3. Cont.

\begin{tabular}{ccccccc}
\hline $\begin{array}{c}\text { Genetic } \\
\text { Model }\end{array}$ & $\begin{array}{c}\text { Patients } \\
(\boldsymbol{n}=\mathbf{6 9 2})\end{array}$ & $\begin{array}{c}\text { Controls } \\
(\boldsymbol{n}=\mathbf{8 7 8})\end{array}$ & $\begin{array}{c}\text { Crude OR } \\
(\mathbf{9 5 \%} \text { CI) }\end{array}$ & $\boldsymbol{p}$ Value & $\begin{array}{c}\text { Adjusted OR } \\
(\mathbf{9 5 \%} \text { CI) }\end{array}$ & $\boldsymbol{p}$ Value \\
\hline $\begin{array}{c}\text { Recessive } \\
\text { AA + AG }\end{array}$ & $636(91.9)$ & $825(94.0)$ & 1.00 & & 1.00 & \\
GG & $56(8.1)$ & $53(6.0)$ & $1.37(0.93-2.02)$ & 0.1127 & $1.37(0.93-2.04)$ & 0.1153 \\
\hline Allelic & & & & & 1.00 & \\
A & $1027(74.2)$ & $1326(75.5)$ & 1.00 & & $1.08(0.97-1.22)$ & 0.1639 \\
G & $357(25.8)$ & $430(24.5)$ & $1.07(0.91-1.26)$ & 0.4014 & 1.00 \\
\hline
\end{tabular}

Abbreviations: MTRR, methionine synthase reductase; OR, odds ratio; CI, confidence interval;

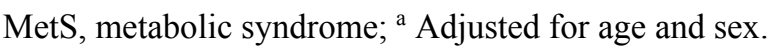

\subsection{Association between Gene Polymorphisms and Metabolic Syndrome (MetS)}

Codominant, dominant, recessive, and allelic genetic models were applied to test the associations of the MTHFR C677T and MTRR A66G polymorphisms with MetS risk. The MTHFR C677T polymorphism was associated with an increased risk of MetS under the homozygous codominant model (odds ratio $(\mathrm{OR})=1.46,95 \%$ confidence interval $(\mathrm{CI})=1.10-1.94, p=0.0097)$, dominant model $(\mathrm{OR}=1.30,95 \% \mathrm{CI}=1.02-1.67, p=0.0355)$, recessive model $(\mathrm{OR}=1.27,95 \% \mathrm{CI}=1.02-1.58$, $p=0.0306)$ and allelic model $(\mathrm{OR}=1.21,95 \% \mathrm{CI}=1.05-1.39, p=0.0086)$ (Table 2). The associations were almost unchanged after adjusting for age and gender (Table 2). With respect to the MTRR A66G polymorphism, no significant association was found under any of the tested genetic models (Table 3).

We then analyzed the association between combined MTHFR C677T and MTRR A66G genotypes and the risk of MetS. By using combined CC/AA genotype as a reference, TT/GG genotype showed a significant association with MetS $(\mathrm{OR}=2.10,95 \% \mathrm{CI}=1.07-4.12, p=0.0307)$ (Table 4). In addition, both TT/AA and TT/AG genotypes showed borderline associations with MetS (OR $=1.46$, $95 \% \mathrm{CI}=0.99-2.16, p=0.0539$, and $\mathrm{OR}=1.52,95 \% \mathrm{CI}=0.98-2.33, p=0.0597$, respectively) (Table 4).

Table 4. Interaction of MTHFR C677T and MTRR A66G polymorphisms on MetS risk.

\begin{tabular}{ccccccc}
\hline $\begin{array}{c}\text { Combined } \\
\text { Genotype }\end{array}$ & $\begin{array}{c}\text { Patients } \\
(\boldsymbol{n}=\mathbf{6 9 2})\end{array}$ & $\begin{array}{c}\text { Controls } \\
(\boldsymbol{n}=\mathbf{8 7 8})\end{array}$ & $\begin{array}{c}\text { Crude OR } \\
(\mathbf{9 5 \%} \text { CI) }\end{array}$ & $\boldsymbol{p}$ Value & $\begin{array}{c}\text { Adjusted OR }^{\text {a }} \\
(\mathbf{9 5 \%} \text { CI) }\end{array}$ & $\boldsymbol{p}$ Value \\
\hline $\mathrm{CC} / \mathrm{AA}$ & $71(10.3)$ & $113(12.9)$ & 1.00 & & 1.00 & \\
$\mathrm{CC} / \mathrm{AG}$ & $46(6.6)$ & $78(8.9)$ & $0.94(0.59-1.50)$ & 0.7916 & $0.98(0.61-1.58)$ & 0.9442 \\
$\mathrm{CC} / \mathrm{GG}$ & $12(1.7)$ & $11(1.3)$ & $1.74(0.73-4.15)$ & 0.2141 & $1.73(0.72-4.18)$ & 0.2198 \\
$\mathrm{CT} / \mathrm{AA}$ & $195(28.2)$ & $248(28.2)$ & $1.25(0.88-1.78)$ & 0.2106 & $1.28(0.90-1.83)$ & 0.1677 \\
$\mathrm{CT} / \mathrm{AG}$ & $121(17.5)$ & $160(18.2)$ & $1.20(0.82-1.76)$ & 0.3382 & $1.26(0.86-1.85)$ & 0.2398 \\
$\mathrm{CT} / \mathrm{GG}$ & $19(2.7)$ & $23(2.6)$ & $1.32(0.67-2.59)$ & 0.4277 & $1.43(0.72-2.83)$ & 0.3116 \\
$\mathrm{TT} / \mathrm{AA}$ & $125(18.1)$ & $140(15.9)$ & $1.42(0.97-2.08)$ & 0.0717 & $1.46(0.99-2.16)$ & 0.0539 \\
$\mathrm{TT} / \mathrm{AG}$ & $78(11.3)$ & $86(9.8)$ & $1.44(0.94-2.21)$ & 0.0917 & $1.52(0.98-2.33)$ & 0.0597 \\
$\mathrm{TT} / \mathrm{GG}$ & $25(3.6)$ & $19(2.2)$ & $2.09(1.08-4.08)$ & 0.0297 & $2.10(1.07-4.12)$ & 0.0307 \\
\hline
\end{tabular}

Abbreviations: MTHFR, methylenetetrahydrofolate reductase; MTRR, methionine synthase reductase; OR, odds ratio; CI, confidence interval; MetS, metabolic syndrome; ${ }^{a}$ Adjusted for age and sex. 


\subsection{Association between Gene Polymorphisms and Individual Components of MetS}

We also investigated the associations of individual components of MetS with the MTHFR C677T and MTRR A66G polymorphisms. Multivariate logistic regression analysis showed that the MTHFR C677T polymorphism increased the risk of high FBG in the homozygous codominant $(\mathrm{OR}=1.83$, 95\% CI $=1.30-2.57, p=0.0005)$, heterozygous codominant $(\mathrm{OR}=1.79,95 \% \mathrm{CI}=1.30-2.45$, $p=0.0003)$, dominant $(\mathrm{OR}=1.80,95 \% \mathrm{CI}=1.34-2.44, p=0.0001)$ and allelic $(\mathrm{OR}=1.28$, $95 \% \mathrm{CI}=1.10-1.50, p=0.0020)$ models, and increased the risk of high $\mathrm{WC}$ in the recessive model $(\mathrm{OR}=1.25,95 \% \mathrm{CI}=1.00-1.57, p=0.0413)$. No significant association was observed between the MTHFR C677T polymorphism and high BP, high TG, and low HDL-C under any of the tested genetic models (Table 5). In addition, we found positive associations between having more MetS components and the MTHFR C677T polymorphism (Table 6).

Table 5. Association of MTHFR C677T and MTRR A66G polymorphisms with individual components of MetS.

\begin{tabular}{|c|c|c|c|c|c|}
\hline \multicolumn{6}{|c|}{ Age and Sex Adjusted OR (95\% CI) } \\
\hline Genetic Model & High BP & High FBG & High TG & Low HDL-C & High WC \\
\hline \multicolumn{6}{|l|}{ MTHFR C677T polymorphism } \\
\hline Homozygous codominant & $\begin{array}{c}1.25 \\
(0.94-1.67)\end{array}$ & $\begin{array}{c}1.83 \\
(1.30-2.57)\end{array}$ & $\begin{array}{c}1.20 \\
(0.87-1.67)\end{array}$ & $\begin{array}{c}1.02 \\
(0.77-1.36)\end{array}$ & $\begin{array}{c}1.33 \\
(0.99-1.79)\end{array}$ \\
\hline Heterozygous codominant & $\begin{array}{c}1.07 \\
(0.82-1.39)\end{array}$ & $\begin{array}{c}1.79 \\
(1.30-2.45)\end{array}$ & $\begin{array}{c}1.29 \\
(0.96-1.74)\end{array}$ & $\begin{array}{c}0.94 \\
(0.72-1.22)\end{array}$ & $\begin{array}{c}1.09 \\
(0.84-1.43)\end{array}$ \\
\hline Dominant & $\begin{array}{c}1.13 \\
(0.88-1.45)\end{array}$ & $\begin{array}{c}1.80 \\
(1.34-2.44)\end{array}$ & $\begin{array}{c}1.26 \\
(0.95-1.67)\end{array}$ & $\begin{array}{c}0.97 \\
(0.76-1.24)\end{array}$ & $\begin{array}{c}1.18 \\
(0.92-1.52)\end{array}$ \\
\hline Recessive & $\begin{array}{c}1.20 \\
(0.96-1.49)\end{array}$ & $\begin{array}{c}1.20 \\
(0.95-1.53)\end{array}$ & $\begin{array}{c}1.01 \\
(0.79-1.28)\end{array}$ & $\begin{array}{c}1.07 \\
(0.86-1.33)\end{array}$ & $\begin{array}{c}1.25 \\
(1.00-1.57)\end{array}$ \\
\hline Allelic & $\begin{array}{c}1.10 \\
(0.96-1.27) \\
\end{array}$ & $\begin{array}{c}1.28 \\
(1.10-1.50) \\
\end{array}$ & $\begin{array}{c}1.06 \\
(0.91-1.24) \\
\end{array}$ & $\begin{array}{c}1.04 \\
(0.90-1.19) \\
\end{array}$ & $\begin{array}{c}1.12 \\
(0.97-1.29) \\
\end{array}$ \\
\hline \multicolumn{6}{|l|}{ MTRR A66G polymorphism } \\
\hline Homozygous codominant & $\begin{array}{c}1.17 \\
(0.78-1.75)\end{array}$ & $\begin{array}{c}1.86 \\
(1.22-2.82)\end{array}$ & $\begin{array}{c}1.61 \\
(1.06-2.46)\end{array}$ & $\begin{array}{c}0.75 \\
(0.50-1.14)\end{array}$ & $\begin{array}{c}0.91 \\
(0.60-1.38)\end{array}$ \\
\hline Heterozygous codominant & $\begin{array}{c}1.11 \\
(0.90-1.38)\end{array}$ & $\begin{array}{c}0.97 \\
(0.77-1.24)\end{array}$ & $\begin{array}{c}0.90 \\
(0.70-1.14)\end{array}$ & $\begin{array}{c}0.86 \\
(0.69-1.06)\end{array}$ & $\begin{array}{c}0.91 \\
(0.73-1.14)\end{array}$ \\
\hline Dominant & $\begin{array}{c}1.12 \\
(0.92-1.38)\end{array}$ & $\begin{array}{c}1.09 \\
(0.87-1.37)\end{array}$ & $\begin{array}{c}0.99 \\
(0.79-1.25)\end{array}$ & $\begin{array}{c}0.84 \\
(0.69-1.03)\end{array}$ & $\begin{array}{c}0.91 \\
(0.74-1.12)\end{array}$ \\
\hline Recessive & $\begin{array}{c}1.12 \\
(0.75-1.67)\end{array}$ & $\begin{array}{c}1.88 \\
(1.25-2.82)\end{array}$ & $\begin{array}{c}1.68 \\
(1.12-2.54)\end{array}$ & $\begin{array}{c}0.80 \\
(0.53-1.19)\end{array}$ & $\begin{array}{c}0.95 \\
(0.63-1.42)\end{array}$ \\
\hline Allelic & $\begin{array}{c}1.07 \\
(0.91-1.26)\end{array}$ & $\begin{array}{c}1.16 \\
(0.97-1.39)\end{array}$ & $\begin{array}{c}1.08 \\
(0.90-1.29)\end{array}$ & $\begin{array}{c}0.88 \\
(0.74-1.03)\end{array}$ & $\begin{array}{c}0.91 \\
(0.78-1.07)\end{array}$ \\
\hline
\end{tabular}

Abbreviations: MTHFR, methylenetetrahydrofolate reductase; MTRR, methionine synthase reductase; OR, odds ratio; CI, confidence interval; BP, blood pressure; FBG, fasting blood pressure; TG, triglycerides; HDL-C, high density lipoprotein cholesterol; WC, waist circumference. 
Table 6. Adjusted odds ratios for MTHFR C677T and MTRR A66G polymorphisms according to the number of components of MetS.

\begin{tabular}{ccccc}
\hline \multicolumn{7}{c}{ Age and Sex Adjusted OR (95\% CI) } \\
\hline Genetic Model & $\geq \mathbf{1}$ Components & $\mathbf{\geq}$ Components & $\mathbf{3}$ Components & $\geq$ 4 Components \\
\hline MTHFR C677T polymorphism & & & & \\
Homozygous codominant & $1.30(0.87-1.95)$ & $1.46(1.08-1.97)$ & $1.50(1.12-2.02)$ & $1.68(1.10-2.27)$ \\
Heterozygous codominant & $1.05(0.74-1.50)$ & $1.26(0.96-1.65)$ & $1.26(0.96-1.66)$ & $1.52(1.02-2.27)$ \\
Dominant & $1.14(0.81-1.59)$ & $1.33(1.03-1.71)$ & $1.35(1.04-1.75)$ & $1.58(1.08-2.31)$ \\
Recessive & $1.26(0.92-1.73)$ & $1.24(0.99-1.56)$ & $1.28(1.02-1.60)$ & $1.24(0.92-1.67)$ \\
Allelic & $1.13(0.93-1.38)$ & $1.17(1.01-1.35)$ & $1.20(1.04-1.39)$ & $1.24(1.01-1.52)$ \\
\hline MTRR A66G polymorphism & & & & \\
Homozygous codominant & $1.43(0.76-2.70)$ & $1.43(0.92-2.23)$ & $1.42(0.95-2.13)$ & $0.80(0.44-1.44)$ \\
Heterozygous codominant & $0.95(0.71-1.28)$ & $0.93(0.75-1.17)$ & $0.92(0.73-1.14)$ & $0.86(0.64-1.17)$ \\
Dominant & $1.01(0.76-1.34)$ & $1.00(0.81-1.23)$ & $0.99(0.80-1.21)$ & $0.85(0.64-1.14)$ \\
Recessive & $1.46(0.79-2.72)$ & $1.47(0.95-2.27)$ & $1.47(0.99-2.19)$ & $0.84(0.47-1.51)$ \\
Allelic & $1.05(0.84-1.32)$ & $1.03(0.88-1.22)$ & $1.04(0.88-1.23)$ & $0.86(0.68-1.09)$ \\
\hline
\end{tabular}

Abbreviations: MTHFR, methylenetetrahydrofolate reductase; MTRR, methionine synthase reductase; OR, odds ratio; CI, confidence interval.

For the MTRR A66G polymorphism, significant associations were found between the polymorphism and high FBG in the homozygous codominant $(\mathrm{OR}=1.86,95 \% \mathrm{CI}=1.22-2.82, p=0.0036)$ and recessive $(\mathrm{OR}=1.88,95 \% \mathrm{CI}=1.25-2.82, p=0.0024)$ models. The polymorphism was also associated with increased risk of high $\mathrm{TG}$ in the homozygous codominant $(\mathrm{OR}=1.61,95 \% \mathrm{CI}=1.06-2.46$, $p=0.0260)$ and recessive $(\mathrm{OR}=1.68,95 \% \mathrm{CI}=1.12-2.54, p=0.0130)$ models. No significant association was observed between the MTRR A66G polymorphism and the remaining three components in any of the tested genetic models (Table 5).

When evaluating the gene-gene interaction, the combined CC/GG, CT/AA, CT/AG, CT/GG, TT/AA, TT/AG and TT/GG genotypes increased the risk of high FBG with an OR of $3.08(95 \% \mathrm{CI}=1.21-7.82$, $p=0.0179), 2.08$ (95\% CI $=1.35-3.21, p=0.0009), 1.94(95 \% \mathrm{CI}=1.22-3.09, p=0.0050)$, $2.90(95 \% \mathrm{CI}=1.37-6.12, p=0.0054), 1.98(95 \% \mathrm{CI}=1.24-3.17, p=0.0040), 1.95(95 \% \mathrm{CI}=1.16-3.26$, $p=0.0112)$, and $3.95(95 \% \mathrm{CI}=1.93-8.05, p=0.0002)$, respectively. And the combined $\mathrm{CT} / \mathrm{GG}$ genotype was associated with increased risk of high $\mathrm{TG}(\mathrm{OR}=2.65,95 \% \mathrm{CI}=1.30-5.41$, $p=0.0072$ ) (Table 7). In addition, the combined TT/GG genotype was associated with a 2.52-fold $(95 \% \mathrm{CI}=1.15-5.51, p=0.0208)$ increased risk of having $\geq 2$ MetS components and a 1.98-fold $(95 \% \mathrm{CI}=1.01-3.89, p=0.0470)$ increased risk of having $\geq 3 \mathrm{MetS}$ components. The CT/AA and TT/AA genotypes were associated with a 2.02-fold $(95 \%=1.15-3.54, p=0.0144)$ and a 2.49 -fold $(95 \% \mathrm{CI}=1.38-4.49, p=0.0024)$ increased risk of having $\geq 4$ MetS components, respectively (Table 8$)$. 
Table 7. Association of combined MTHFR C677T and MTRR A66G genotypes with MetS.

\begin{tabular}{cccccc}
\hline \multicolumn{7}{c}{ Age and Sex Adjusted OR with 95\% CI } \\
\hline Combined Genotype & High BP & High FBG & High TG & Low HDL-C & High WC \\
\hline CC/AA & 1.00 & 1.00 & 1.00 & 1.00 & 1.00 \\
& 1.32 & 1.13 & 1.04 & 0.90 & 0.77 \\
CC/AG & $(0.83-2.11)$ & $(0.63-2.06)$ & $(0.60-1.78)$ & $(0.56-1.43)$ & $(0.48-1.23)$ \\
& 1.75 & 3.08 & 1.84 & 0.69 & 1.46 \\
CC/GG & $(0.72-4.28)$ & $(1.21-7.82)$ & $(0.72-4.71)$ & $(0.28-1.70)$ & $(0.58-3.66)$ \\
& 1.19 & 2.08 & 1.33 & 0.93 & 1.10 \\
CT/AA & $(0.83-1.69)$ & $(1.35-3.21)$ & $(0.89-1.98)$ & $(0.66-1.32)$ & $(0.77-1.57)$ \\
& 1.36 & 1.94 & 1.30 & 0.79 & 0.96 \\
CT/AG & $(0.93-1.98)$ & $(1.22-3.09)$ & $(0.84-2.00)$ & $(0.54-1.16)$ & $(0.65-1.41)$ \\
& 0.94 & 2.90 & 2.65 & 0.89 & 0.64 \\
CT/GG & $(0.47-1.88)$ & $(1.37-6.12)$ & $(1.30-5.41)$ & $(0.45-1.76)$ & $(0.32-1.31)$ \\
& 1.44 & 1.98 & 1.41 & 1.06 & 1.18 \\
TT/AA & $(0.98-2.11)$ & $(1.24-3.17)$ & $(0.92-2.18)$ & $(0.72-1.56)$ & $(0.79-1.75)$ \\
& 1.36 & 1.95 & 0.98 & 0.89 & 1.34 \\
TT/AG & $(0.88-2.10)$ & $(1.16-3.26)$ & $(0.59-1.62)$ & $(0.58-1.37)$ & $(0.86-2.09)$ \\
& 1.87 & 3.95 & 1.70 & 0.64 & 1.25 \\
TT/GG & $(0.95-2.04)$ & $(1.93-8.05)$ & $(0.83-3.49)$ & $(0.32-1.28)$ & $(0.63-2.51)$ \\
\hline
\end{tabular}

Abbreviations: MTHFR, methylenetetrahydrofolate reductase; MTRR, methionine synthase reductase; OR, odds ratio; CI, confidence interval; BP, blood pressure; FBG, fasting blood pressure; TG, triglycerides; HDL-C, high density lipoprotein cholesterol; WC, waist circumference.

Table 8. Adjusted odds ratios for combined MTHFR C677T and MTRR A66G genotypes according to the number of components of MetS.

\begin{tabular}{ccccc}
\hline \multicolumn{5}{c}{ Age and Sex Adjusted OR (95\% CI) } \\
\hline Combined Genotype & $\geq \mathbf{1}$ Components & $\geq \mathbf{2}$ Components & $\geq \mathbf{3}$ Components & $\geq$ 4 Components \\
\hline $\mathrm{CC} / \mathrm{AA}$ & 1.00 & 1.00 & 1.00 & 1.00 \\
$\mathrm{CC} / \mathrm{AG}$ & $0.79(0.43-1.44)$ & $0.91(0.57-1.45)$ & $0.88(0.54-1.45)$ & $1.57(0.76-3.25)$ \\
$\mathrm{CC} / \mathrm{GG}$ & $3.95(0.51-30.65)$ & $1.73(0.66-4.50)$ & $1.89(0.78-4.58)$ & $1.57(0.42-5.86)$ \\
$\mathrm{CT} / \mathrm{AA}$ & $0.99(0.61-1.60)$ & $1.25(0.87-1.79)$ & $1.31(0.91-1.88)$ & $2.02(1.15-3.54)$ \\
$\mathrm{CT} / \mathrm{AG}$ & $1.01(0.60-1.70)$ & $1.26(0.85-1.86)$ & $1.15(0.78-1.71)$ & $1.74(0.95-3.18)$ \\
$\mathrm{CT} / \mathrm{GG}$ & $1.21(0.46-3.17)$ & $1.34(0.66-2.74)$ & $1.61(0.81-3.24)$ & $1.45(0.50-4.21)$ \\
$\mathrm{TT} / \mathrm{AA}$ & $1.24(0.72-2.13)$ & $1.47(0.99-2.21)$ & $1.46(0.98-2.16)$ & $2.49(1.38-4.49)$ \\
$\mathrm{TT} / \mathrm{AG}$ & $1.24(0.68-2.29)$ & $1.25(0.80-1.96)$ & $1.47(0.94-2.29)$ & $1.57(0.80-3.11)$ \\
$\mathrm{TT} / \mathrm{GG}$ & $1.39(0.50-3.86)$ & $2.52(1.15-5.51)$ & $1.98(1.01-3.89)$ & $1.58(0.58-4.31)$ \\
\hline
\end{tabular}

Abbreviations: MTHFR, methylenetetrahydrofolate reductase; MTRR, methionine synthase reductase; OR, odds ratio; CI, confidence interval.

\section{Discussion}

MetS is caused by the interplay of multiple genetic and environmental factors [6]. A growing body of evidence has linked HHcy with MetS and its individual components [7-13,34]. Although the precise mechanism by which HHcy promotes these disorders remains unclear, some investigators have proposed possibilities including promoting endothelial dysfunction, inducing insulin resistance, 
and affecting DNA methylation status [10,14-17]. The MTHFR C677T and MTRR A66G polymorphisms are important genetic risk factors for HHcy $[18,21]$ and are considered to be associated with DNA hypomethylation, indicating that they may serve as potential determinants of MetS. To our knowledge, this is the first study to investigate the possible relationships of the MTHFR C677T and MTRR A66G polymorphisms with MetS among the Chinese Han population. We found that the MTHFR 677T allele carriers had an increased risk of MetS, and the 677TT genotype showed a significant correlation with high FBG, high WC, and having more MetS components, respectively. No association was observed between the MTRR A66G polymorphism and MetS. However, the 66GG genotype showed a significant association with high FBG and TG. Additionally, the MTRR A66G polymorphism may interact with the MTHFR 677TT genotype conferring a higher risk of MetS.

Many previous studies have investigated the relationships of the MTHFR C677T polymorphism with MetS and its individual components [22-24]. Three studies conducted respectively in type 2 diabetes, schizophrenia and colorectal cancer patients reported no relationship of the MTHFR C677T polymorphism with MetS [26,28,30]. On the contrary, Elligrond et al. [27] reported that schizophrenic patients carrying the $677 \mathrm{~T}$ allele had an increased risk of MetS, and Kim et al. [29] observed that the 677T allele was associated with an increased risk of MetS compared to the $677 \mathrm{C}$ allele among Korean ischemic stroke patients. Additionally, two studies conducted, respectively, in Iran and in Greece, have investigated the relationship of the MTHFR C677T polymorphism with MetS among general population without severe diseases [24,35]. The MTHFR C677T polymorphism was found to be not significantly associated with MetS among the Iranian population [35], however, the 677T allele showed a 4.02-fold increased risk of MetS among the Greek population [24]. In agreement with the findings of Vasilopoulos et al. [24], Elligrond et al. [27] and Kim et al. [29], our results showed a strong association between the MTHFR 677T allele and MetS, suggesting that the allele might be a genetic risk factor for MetS in the Northern Chinese Han population. Many factors may contribute to the inconsistencies between our results and those reported by the aforementioned published studies. Firstly, genetic backgrounds, which can have an influence on disease susceptibility, are different among populations. Secondly, different populations have different dietary habits (such as intake of folate, vitamin $\mathrm{B}_{2}$ and vitamin $\mathrm{B}_{12}$ ) and environmental exposures, which may affect the association between the polymorphism and MetS through epigenetic mechanisms. Thirdly, some of these studies had relatively small sample sizes, which may lack sufficient power to deny or support an association. Fourthly, some studies are conducted in specific populations with various diseases like type 2 diabetes, schizophrenia, cancer and stroke, while others, including our study, were conducted among general population without any severe diseases, indicating that medication or other clinical factors might also have contributed to the inconsistencies. Lastly, differences in diagnostic criteria for MetS, mean age of the participants and sex proportion may also be responsible. In the analysis of the individual MetS components, the MTHFR 677TT genotype exhibited a significant association with high FBG, which is consistent with the results of previous studies $[23,36]$. These results could be explained by detrimental impact of Hcy on insulin secretion and pancreatic beta cell function [37,38]. Elevated Hcy levels caused by the MTHFR genetic variants have been demonstrated as related to insulin resistance, which is the major cause of high FBG or diabetes [39]. In addition, the correlation between the MTHFR 677T allele and DNA hypomethylation, which is suggested to be related to pathogenesis of diabetes, may be another possible explanation $[15,19]$. We also found a positive correlation between the MTHFR $677 \mathrm{~T}$ allele and a higher likelihood of 
high WC. The link between the two has been investigated by several previous studies; however, the results were inconsistent $[24,25,40]$. Further studies therefore are still required to confirm or refute our findings.

The information about the effect of the MTRR A66G polymorphism on MetS and its individual components is limited. A recent study by Jiang et al. [41] reported that the 66GG genotype carriers had lower TC and LDL-C levels in comparison to those with the 66AA genotype in Chinese hypertensive patients. Another study of an Australian sample [42] found no association between the MTRR A66G polymorphism and the risk of hypertension. To our knowledge, this is the first study to evaluate the effect of the MTRR A66G polymorphism on susceptibility to MetS. Our study failed to find any association between the MTRR A66G polymorphism alone and the risk of MetS. However, it is noteworthy that the MTRR A66G polymorphism was associated with an increased risk of MetS when combined with the MTHFR 677TT genotype. Furthermore, our OR results evidently showed that the combined TT/GG, TT/AG and TT/AA genotypes conferred higher risk of MetS than the MTHFR C677T mutant genotypes alone. These data suggest that there might exist a synergistic effect of these two polymorphisms upon MetS causation. It was reported in several previous studies that the effect of the MTRR A66G polymorphism on plasma Hcy concentrations is weak [43], whereas coexistence of the MTHFR C677T and MTRR A66G polymorphisms was associated with an increased risk of HHcy compared to either the MTHFR C677T or MTRR A66G polymorphism alone [21,44]. Thus, it seems that the lack of correlation between the MTRR A66G polymorphism and MetS in our study may be due to its weak effect on plasma Hcy concentrations, and the synergistic effect of the two polymorphisms on MetS may be due to their interactive effect on Hcy concentrations. Analyses of the individual MetS components showed that the MTRR 66GG genotype was significantly associated with high FBG and TG. To the best of our knowledge, this is the first study reporting positive relationships of the MTRR A66G polymorphism with high FBG and TG. However, these results should be interpreted with great caution because the frequency of the MTRR 66GG genotype is relatively lower in our study. Therefore, further studies with larger sample sizes will be needed to confirm these findings.

In interpreting the findings of our study, several limitations should be acknowledged. Firstly, the study subjects were from one hospital, indicating that they may not be fully representative of the general population. Moreover, only two polymorphisms were explored for their associations with MetS, not all of the polymorphisms reported in the literature, indicating that gene-gene interactions may not be fully explored. Thirdly, information on environmental factors such as diet or behavior was not available, which suggests the effect of gene-environmental interactions may not be identified in the study. Despite the limitations, our study still has several strengths: (1) exploring the relationships of the MTHFR C677T and MTRR A66G polymorphisms with MetS for the first time in a Chinese population; (2) having large sample sizes, thus ensuring enough power to reduce type I error; (3) selecting ethnically homogeneous population (Chinese Han), thus improving the validity of statistical analysis. 


\section{Experimental Section}

\subsection{Ethics Statement}

The study was conducted in accordance with the principles stipulated by the Declaration of Helsinki and all procedures were approved by the ethics review committee of China Medical University (Shenyang, China; Identification code: CMU62073024; 15 July 2008). All specimens and survey data were obtained with written informed consent from all participants prior to study entry and subsequently anonymised.

\subsection{Study Subjects}

Between October 2008 and February 2011, a total of 692 MetS patients and 878 healthy controls who took regular physical examination at the physical examination center of Dagang Oil Field General Hospital were recruited into our study. Patients and controls were frequency-matched according to age ( \pm 5 years) and sex. All subjects were genetically unrelated ethnic Han Chinese and resided in the Dagang district of Tianjin municipality, northern China. Main exclusion criteria included a history of myocardial infarction, stroke, diabetes, any type of cancer, and renal failure or chronic liver disease. Weight, height and WC were measured using a standard scale with light clothing and barefoot after an overnight fast. At the same time, participants were asked for permission to store a blood sample for biochemical analysis and a buccal cell sample for genetic analysis. BMI was calculated as weight in kilograms divided by the square of height in meters $\left(\mathrm{kg} / \mathrm{m}^{2}\right)$. BP was measured while subjects were in the sitting position after $15 \mathrm{~min}$ of rest. The average of three measurements was recorded.

\subsection{Biomedical Measurements}

The levels of TC, HDL-C, LDL-C, TG and FBG in samples were determined by enzymatic method using a Hitachi Autoanalyzer (Type 7170A; Hitachi Ltd., Tokyo, Japan) in Dagang Oil Field General Hospital. All assays were performed according to the manufacturer's instructions.

\subsection{Definition of the MetS}

MetS was defined using the Updated National Cholesterol Education Program/Adult Treatment Panel III Criteria for Asian Americans as having at least three of the following components: (1) BP of at least 130/85 mmHg and/or on antihypertensive medications; (2) TG of at least $1.7 \mathrm{mmol} / \mathrm{L}$; (3) HDL-C less than $1.03 \mathrm{mmol} / \mathrm{L}$ for males and less than $1.30 \mathrm{mmol} / \mathrm{L}$ for females; (4) $\mathrm{FBG}$ of at least $5.6 \mathrm{mmol} / \mathrm{L}$ or taking medication for diabetes mellitus; (5) WC greater than $90 \mathrm{~cm}$ for males and greater than $80 \mathrm{~cm}$ for females [45].

\subsection{Genotyping}

Genomic DNA was extracted from buccal samples using the QIAamp DNA Mini Kit (Qiagen, Valencia, CA, USA). Genotyping for the MTHFR C677T and MTRR A66G polymorphisms was performed as described in our previous paper [33]. 


\subsection{Statistical Analysis}

The MTHFR C677T and MTRR A66G allele and genotype frequencies in the patients and controls were calculated by direct counting. $\chi^{2}$ analysis was performed to identify departure from the Hardy-Weinberg equilibrium, and to compare the differences between the two groups with respect to allelic and genotypic frequencies. The unconditional logistic regression analysis was performed to estimate the effects of the MTHFR C677T and MTRR A66G polymorphisms singly and in combination on MetS and its individual components after adjustment for age and sex. The OR with 95\% CI was calculated to estimate the relative risk of the different genotypes and alleles. A $p$ value below 0.05 was taken as statistically significant. All analyses were performed using SAS version 9.2 (SAS Institute, Cary, NC, USA).

\section{Conclusions}

In conclusion, in this study we found a significant association between the MTHFR 677T allele and MetS, high FBG, high WC, and increasing number of MetS components in a Chinese Han population. The MTRR A66G polymorphism was not associated with MetS. However, there might exist an interactive effect of the MTHFR C677T and MTRR A66G polymorphisms on MetS. Furthermore, the MTRR 66GG genotype showed a significant association with high FBG and TG. These findings are of significance, as these are valuable for the early identification of individuals at high risk for MetS in later life and for motivating them to adopt a healthy lifestyle (such as folic acid fortification) to reduce the risk. However, as in any study examining genotype-phenotype relationships, replication of the current study is required. Therefore, further large prospective population-based studies are required to confirm our findings.

\section{Acknowledgments}

We gratefully acknowledge the assistance and cooperation of the faculty and staff of Dagang Oil Field General Hospital and thank all of the participants in our study. We also thank Yi Zheng from the Third Military Medical University for her careful reading of the drafts of this manuscript and helpful suggestions.

\section{Author Contributions}

Boyi Yang and Guifan Sun conceived the study design and wrote the paper. Shujun Fan, Xueyuan Zhi, Da Wang, Yongfang Li, and Jian Wei performed the experiments, collected the data, and performed the statistical analysis. Yinuo Wang, Yanxun Wang, and Quanmei Zheng were responsible for the quality control of data. All authors read and approved the final manuscript.

\section{Conflicts of Interest}

The authors declare no conflict of interest. 


\section{References}

1. Alberti, K.G.; Eckel, R.H.; Grundy, S.M.; Zimmet, P.Z.; Cleeman, J.I.; Donato, K.A.; Fruchart, J.C.; James, W.P.; Loria, C.M.; Smith, S.C. Harmonizing the metabolic syndrome: A joint interim statement of the International Diabetes Federation Task Force on Epidemiology and Prevention; National Heart, Lung, and Blood Institute; American Heart Association; World Heart Federation; International Atherosclerosis Society; and International Association for the Study of Obesity. Circulation 2009, 120, 1640-1645.

2. Grundy, S.M. Metabolic syndrome pandemic. Arterioscler. Thromb. Vasc. Biol. 2008, 28, 629-636.

3. Gu, D.; Reynolds, K.; Wu, X.; Chen, J.; Reynolds, R.F.; Whelton, P.K.; He, J.; InterASIA Collaborative Group. Prevalence of the metabolic syndrome and overweight among adults in China. Lancet 2005, 365, 1398-1405.

4. Isomaa, B.; Almgren, P.; Tuomi, T.; Forsen, B.; Lahti, K.; Nissen, M.; Taskinen, M.R.; Groop, L. Cardiovascular morbidity and mortality associated with the metabolic syndrome. Diabetes Care 2001, 24, 683-689.

5. Lorenzo, C.; Williams, K.; Hunt, K.J.; Haffner, S.M. The National Cholesterol Education Program-Adult Treatment Panel III, International Diabetes Federation, and World Health Organization definitions of the metabolic syndrome as predictors of incident cardiovascular disease and diabetes. Diabetes Care 2007, 30, 8-13.

6. Cornier, M.A.; Dabelea, D.; Hernandez, T.L.; Lindstrom, R.C.; Steig, A.J.; Stob, N.R.; van Pelt, R.E.; Wang, H.; Eckel, R.H. The metabolic syndrome. Endocr. Rev. 2008, 29, 777-822.

7. Meigs, J.B.; Jacques, P.F.; Selhub, J,; Singer, D.E.; Nathan, D.M.; Rifai, N.; D’Agostino, R.B.; Wilson, P.W.; Framingham offspring study. Fasting plasma homocysteine levels in the insulin resistance syndrome: The Framingham offspring study. Diabetes Care 2001, 24, 1403-1410.

8. Obeid, R.; Herrmann, W. Homocysteine and lipids: $S$-Adenosyl methionine as a key intermediate. FEBS Lett. 2009, 583, 1215-1225.

9. Wilson, C.P.; McNulty, H.; Scott, J.M.; Strain J.J.; Ward, M. Postgraduate symposium: The MTHFR C677T polymorphism, B-vitamins and blood pressure. Proc. Nutr. Soc. 2010, 69, $156-165$.

10. Bjorck, J.; Hellgren, M.; Rastam, L.; Linblad, U. Associations between serum insulin and homocysteine in a Swedish population-A potential link between the metabolic syndrome and hyperhomocysteinemia: The Skaraborg project. Metabolism 2006, 55, 1007-1013.

11. Guven, A.; Inanc, F.; Kilinc, M.; Ekerbicer, H. Plasma homocysteine and lipoprotein (a) levels in Turkish patients with metabolic syndrome. Heart Vessels 2005, 20, 290-295.

12. Expert Pannel on Detection, Evaluation, and Treatment of High Blood Cholesterol in Adults. Executive Summary of the Third Report of the National Cholesterol Education Program (NCEP) Expert Panel on Detection, Evaluation, and Treatment of High Blood Cholesterol in Adults (Adult Treatment Panel III). JAMA 2001, 285, 2486-2497. Available online: http://jama.jamanetwork.com/ article.aspx?articleid=193847 (accessed on 5 July 2014). 
13. Oron-Herman, M.; Rosenthal, T.; Sela, B.A. Hyperhomocysteinemia as a component of syndrome X. Metabolism 2003, 52, 1491-1495.

14. Yi, P.; Melnyk, K.; Pogribna, M.; Pogribny, I.P.; Hine, R.J.; James, S.J. Increase in plasma homocysteine associated with parallel increases in plasma $S$-adenosylhomocysteine and lymphocyte DNA hypomethylation. J. Biol. Chem. 2000, 38, 29318-29323.

15. Luttmer, R.; Spijkerman, A.M.; Kok R.M.; Jakobs, C.; Blom, H.J.; Serne, E.H.; Dekker, J.M.; Smulders, Y.M. Metabolic syndrome components are associated with DNA hypomethylation. Obes. Res. Clin. Pract. 2013, 2, e106-e115.

16. Zhang, B.; Qiu, L.; Fu, M.; Hu, S. Interference in mevalonate pathway ameliorates homocysteine-induced endothelium-dysfunction. Eur. J. Pharmacol. 2012, 692, 61-68.

17. Najib, S.; Sanchez-Margalet, V. Homocysteine thiolactone inhibits insulin-stimulated DNA and protein synthesis: Possible role of mitogen-activated protein kinase (MAPK), glycogen synthase kinase-3 (GSK-3) and p70 S6K phosphorylation. J. Mol. Endocrinol. 2005, 34, 119-126.

18. Rozen, R. Genetic predisposition to hyperhomocysteinemia: Deficiency of methylenetetrahydrofolate reductase (MTHFR). Throm. Haemost. 1997, 78, 523-526.

19. Weiner, A.S.; Boyarskikh, U.A.; Voronina, E.N.; Mishukova, O.V.; Filipenko, M.L. Methylenetetrahydrofolate reductase C677T and methionine synthase A2756G polymorphisms influence on leukocyte genomic DNA methylation level. Gene 2014, 1, 168-172.

20. Gaughan, D.J.; Kluijtmans, L.A.; Barbaux, S.; MaMaster, D.; Young, J.W.; Evan, A.; Whitehead, A.S. The methionine synthase reductase (MTRR) A66G polymorphism is a novel genetic determinant of plasma homocysteine concentrations. Atherosclerosis 2001, 157, 451-456.

21. Vaughn, J.D.; Bailey, L.B.; Shelnutt, K.P.; Dunwoody, K.M.; Maneval, D.R.; Davis, S.R.; Quinlivan, E.P.; Gregory, J.F.; Kauwell, G.P. Methionine synthase reductase 66A $\rightarrow \mathrm{G}$ polymorphism is associated with increased plasma homocysteine concentration when combined with the homozygous methylenetetrahydrofolate reductase $677 \mathrm{C} \rightarrow \mathrm{T}$ variant. J. Nutr. 2004, 134, 2985-2990.

22. Yang, B.Y.; Fan, S.J.; Zhi, X.Y.; Li, Y.F.; Liu, Y.Y.; Wang, D.; He, M.; Hou, Y.Y.; Zheng, Q.M.; Sun, G.F. Associations of MTHFR gene polymorphisms with hypertension and hypertension in pregnancy: A meta-analysis from 114 studies with 15411 cases and 21970 controls. PLoS One 2014, 9, e87497.

23. Huang, T.; Ren, J.; Huang, J.; Li, D. Association of homocysteine with type 2 diabetes: A meta-analysis implementing mendelian randomization approach. BMC Genomics 2013, 14, 867.

24. Vasilopoulos,Y.; Sarafidou, T.; Bagiatis, V.; Skriapa, L.; Goutzelas, Y.; Pervanidou, P.; Lazopoulou, N.; Chrousos, G.P.; Mamuris, Z. Association between polymorphisms in MTHFR and APOA5 and metabolic syndrome in the Greek population. Genet. Test. Mol. Biomark. 2011, 15, 613-617.

25. Lewis, S.J.; Lawlor, D.A.; Nordestgaard, B.G.; Tybjaerg-Hansen A,; Ebrahim, S.; Zacho, J.; Ness, A.; Leary, S.; Smith, G.D. The methylenetetrahydrofolate reductase C677T genotype and the risk of obesity in three large population-based cohorts. Eur. J. Endocrinol. 2008, 159, 35-40.

26. Van Winkel, R.; Rutten, B.P.; Peerbooms, O.; Peuskens J.; van Os, J.; de Hert, M. MTHFR and risk of metabolic syndrome in patients with schizophrenia. Schizophr. Res. 2010, 121, 193-198. 
27. Ellingrod, V.L.; Miller, D.D.; Taylor, S.F.; Moline, J.; Kerr, J. Metabolic syndrome and insulin resistance in schizophrenia patients receiving antipsychotics genotyped for the methylenetetrahydrofolate reductase (MTHFR) $677 \mathrm{C} / \mathrm{T}$ and $1298 \mathrm{~A} / \mathrm{C}$ variants. Schizophr. Res. 2008, 98, 47-54.

28. Russo, G.T.; di Benedetto, A.; Alessi, E.; Inentile, R.; Antico, A.; Nicocia, G.; la Scala, R.; di Cesare, E.; Raimondo, G.; Cucinotta, D. Mild hyperhomocysteinemia and the common C677T polymorphism of methylenetetrahydrofolate reductase gene are not associated with the metabolic syndrome in Type 2 diabetes. J. Endocrinol. Investig. 2006, 29, 201-207.

29. Kim, O.J.; Hong, S.H.; Jeon, Y.J.; Oh, S.H.; Park, Y.S.; Kim, E.J.; Kim, N.K. Gene-environment interactions between methylenetetrahydrofolate reductase $(M T H F R) \quad 677 \mathrm{C} \rightarrow \mathrm{T}$ and metabolic syndrome for the prevalence of ischemic stroke in Koreans. Neurosc. Lett. 2013, 533, 11-16.

30. Kang, B.S.; Ahn, D.H.; Kim, N.K.; Kim, J.W. Relationship between metabolic syndrome and MTHFR polymorphism in colorectal cancer. J. Korean Soc. Coloproctol. 2011, 27, 78-82.

31. The World Bank. Toward a healthy and harmonious life in China: Stemming the rising tide of non-communicable disease. Available online: http://www.worldbank.org/en/news/2011/07/26/ toward-health-harmonious-life-china-stemming-rising-tide-of-non-communicable-diseases (accessed on 10 August 2014).

32. Hao, L.; Ma, J.; Zhu, J.; Stampfer, M.J.; Tian, Y.; Willett, W.C.; Li, Z. High prevalence of hyperhomocysteinemia in Chinese adults is associated with low folate, vitamin B-12, and vitamin B-6 status. J. Nutr. 2007, 137, 407-413.

33. Yang, B.Y.; Liu, Y.Y.; Li, Y.F.; Fan, S.J.; Lu, X.X.; Wang, D.; Zheng, Q.M.; Wang, Y.N.; Wang, Y.X.; Sun, G. Geographical distribution of MTHFR C677T, A1298C and MTRR A66G gene polymorphisms in China: Findings from 15357 adults of Han nationality. PLoS One 2013, 8, e57917.

34. Rhee, E.J.; Hwang, S.T.; Lee, W.Y.; Yoon, J.H.; Kim, B.J.; Kim, B.S.; Kang, J.H.; Lee, M.H.; Park, J.R.; Sun, K.C. Relationship between metabolic syndrome categorized by newly recommended by International Diabetes Federation criteria with plasma homocysteine concentration. Endocr. J. 2007, 54, 995-1002.

35. Fakhrzade, H.; Mirarefin, M.; Sharifi, F.; Ghotbi, S.; RezaeiHemami, M.; Mohammad Amoli, M.; Pourebrabrahim, R.; Nouri, M.; TavakkolyBazzaz, J.; Shafaee, A. Association of methylenetetrahydrofolate reductase gene polymorphism (C677T) with metabolic syndrome in an Iranian population: Tehran homocysteine study. Iran J. Diatebes Lipids Disord. 2009, 8, 37-46.

36. Zhu, B.; Wu, X.; Zhi, X.; Liu, L.; Zheng, Q.; Sun, G. Methylenetetrahydrofolate reductase C677T polymorphism and type 2 diabetes mellitus in Chinese population: A meta-analysis of 29 case-controls studies. PLoS One 2014, 7, e102443.

37. Patterson, S.; Flatt, P.R.; McClenaghan, N.H. Homocysteine-induced impairment of insulin secretion from clonal pancreatic BRIN-BD $11 \beta$-cells is not prevented by catalase. Pancreas 2007, $1,144-151$.

38. Scullion, S.M.; Gurful-Convey, E.; Elsner, M.; Lenzen, S.; Flatt, P.R.; McClenaghan, N.H. Enhancement of homocysteine toxicity to insulin-secreting BRIN-BD11 cells in combination with alloxan. J. Endocrinol. 2012, 2, 233-238. 
39. Nafiye, Y.; Sevtap, K.; Muammer, D.; Emre, O.; Senol, K.; Leyla, M. The effect of serum and intrafollicular insulin resistance parameters and homocysteine levels of nonobese, nonhyperandrogenemic polycystic ovary syndrome patients on in vitro fertilization outcomes. Fertil. Steril. 2010, 6, 1864-1869.

40. Terruzzi, I.; Senesi, P.; Fermo, I.; Lattuada, G.; Luzi, L. Are genetic variants of the methyl group metabolism enzymes risk factors predisposing to obesity? J. Endocrinol. Investig. 2007, 9, 747-753.

41. Jiang, S.; Zhao, R.; Pan, M.; Venners, S.A.; Zhong, G.; Hsu, Y.H. Associations of MTHFR and MTRR Polymorphisms with serum lipid levels in Chinese hypertensive patients. Clin. Appl. Thromb. Hemost. 2014, 4, 200-210.

42. Fowdar, J.Y.; Lason, M.V.; Szvetko, A.L.; Lea, R.A.; Griffiths, L.R. Investigation of homocysteine-pathway-related variants in essential hypertension. Int. J. Hypertens. 2012, 2012, 190923.

43. Jacques, P.F.; Bostom, A.G.; Selhub, J.; Rich, S.; Elison, R.C.; Eckfeldt, J.H.; Gravel, R.A.; Rozen, R.; National Heart, Lung; Blood Institute; et al. Effects of polymorphisms of methionine synthase and methionine synthase reductase on total plasma homocysteine in the NHLBI Family Heart Study. Atherosclerosis 2003, 166, 49-55.

44. Barbosa, P.R.; Stabler, S.P.; Machado, A.L.; Braga, R.C.; Hirata, R.D.; Hirata, M.H.; Sampaio-Neto, L.F.; Allen, R.H.; Guerra-Shinohara, E.M. Association between decreased vitamin levels and MTHFR, MTR and MTRR gene polymorphisms as determinants for elevated total homocysteine concentrations in pregnant women. Eur. J. Clin. Nutr. 2008, 62, 1010-1021.

45. Grundy, S.M.; Cleeman, J.I.; Daniels, S.R.; Donato, K.A.; Eckel, R.H.; Franklin, B.A.; Gordon, D.J.; Krauss, R.M.; Savage, P.J.; Smith, S.C. Jr.; et al. Diagnosis and management of the metabolic syndrome: An American Heart Association/National Heart, Lung, and Blood Institute Scientific Statement. Circulation 2005, 112, 2735-2752.

(C) 2014 by the authors; licensee MDPI, Basel, Switzerland. This article is an open access article distributed under the terms and conditions of the Creative Commons Attribution license (http://creativecommons.org/licenses/by/4.0/). 